\title{
POLA PEMANFAATAN ALUN-ALUN SEBAGAI RUANG TERBUKA PUBLIK DI KOTA MAGELANG
}

\section{Refranisa}

Program Studi Arsitektur, Institut Teknologi Indonesia

Penulis korespondensi: Refranisa, Refranisa@iti.ac.id

Naskah diajukan pada: 23 September 2020

Naskah revisi akhir diterima pada: 10 Mei 2021

\begin{abstract}
Abstrak
Alun - alun kota Magelang merupakan salah satu ruang terbuka publik sekaligus Landmark Kota yang sering dikunjung oleh banyak orang, dimana banyak orang melakukan kegiatan sosial, ekonomi, dan berwisata. Setting lingkungan yang ditawarkan pada ruang terbuka publik mempengaruhi bagaimana pelakunya berkegiatan. Adanya kegiatan atraksi wisata, kuliner, permainan anak, dan olahraga menimbulkan adanya pola pemanfaatan ruang yang terjadi pada kawasan tersebut. Pola yang terebentuk didominasi oleh pelaku dan aktivitas yang menimbulkan intensitas kepadatan pada area tertentu. Metode analisis yang digunakan adalah teknik behavioral mapping yang bertujuan untuk menggambarkan pola pemanfaatan ruang didalam sebuah peta kemudian mengidentifikasi frekuensi pelaku dan aktivitas yang dilakukan serta menunjukan kaitannya dengan setting lingkungan yang ditawarkan. Tujuan penelitian ini adalah untuk mengetahui pola pemanfaatan ruang pada area tertentu kemudian memberikan berupa usulan desain yang dapat menunjang kegiatan pelaku dan aktifitas pada alun - alun Kota Magelang. Hasil temuan yang didapat adalah dapat diketahui bahwa, intensitas pemanfaatan ruang tertinggi terdapat pada setting fisik dancing fountain sebagai atraksi wisata yang dapat dinikmati oleh semua kalangan pengguna pada periode waktu akhir pekan.
\end{abstract}

Kata-kata Kunci: Ruang Terbuka Publik, Pola Aktivitas, Behavioral Mapping

\section{THE PATTERN OF UTILIZING THE PLANES AS A PUBLIC OPEN SPACE IN MAGELANG CITY}

\begin{abstract}
Magelang City Square is one of the public open spaces as well as a City Landmark that is often visited by many people, where many people carry out social, economic, and tour activities. Environmental settings offered in public open spaces affect how the perpetrators carry out activities. The activities of tourist attractions, culinary delights, children's games, and sports have led to a pattern of spatial use that occurs in the area. The formed pattern is dominated by actors and activities that cause density intensity in certain areas. The analytical method used is the behavioral mapping technique which aims to describe the pattern of spatial use in a map, then identify the frequency of actors and activities carried out and show their relation to the environmental setting offered. The purpose of this study is to determine the pattern of space utilization in a certain area and then provide a form of design proposals that can support the activities of the actors and activities in Magelang City Square. The findings show that the highest intensity of space utilization is
\end{abstract}


found in the physical setting of the dancing fountain as a tourist attraction that can be enjoyed by all users during the weekend.

Keywords: Public Open Space, Activity Patterns, Behavioral Mapping

\section{Pendahuluan}

Alun-alun kota Magelang merupakan landmark atau icon sekaligus daya tarik wisata di yang mewadahi berbagai aktivitas masyarakat baik pada pagi hari, siang hari, maupun malam hari. Karena adanya berbagai fasilitas yang ditawarkan membuat alun-alun kota Magelang menjadi pusat aktivitas sekaligus tempat melepas lelah bagi masyarakat. Semenjak tahun 2015, Alun alun dinobatkan sebagai image city branding kota magelang sebagai upaya mempromosikan Magelang pada program visit magelang. Pada awal tahun 2017 dibangun satu atraksi menarik yaitu "dancing fountain" sebagai daya tarik obyek utama untuk menarik para wisatawan yang berkunjung. Pada Kondisi sekarang ini pemerintah kota Magelang sedang melakukan pengembangan sarana dan prasaran pada alun-alun kota Magelang.

Setting lingkungan yang ditawarkan didalam alun - alun kota Magelang mempengaruhi bagaimana pelakunya berkegiatan dalam lingkungan tersebut. Kegiatan yang dilakukan diantaranya adalah berolahraga, bermain, berjualan, bersantai, kuliner dan lain sebagainya. Kegitan tersebut tersebar diberbagai titik area dan memiliki daya tarik yang berbeda-beda sehingga muncul pemanfaatan ruang akibat aktivitas tertentu. Area berkegiatan yang memiliki daya tarik tertinggi cenderung memiliki frekuensi yang padat dalam hal pemanfaatan ruang. Adanya perbedaan frekuensi penggunan ruang pada waktu dan tempat tertentu membentuk suatu pola pemanfaatan ruang pada alun-alun kota Magelang. Keberadaan ruang sangatlah penting sebagai salah satu hubungan arsitektur karena fungsinya sebagai wadah kegiatan manusia. Keberadaan ruang juga menimbulkan adanya pola aktivitas yang menyangkut pergerakan manusia didalamnya (Anggita \& Ardiana , 2017). Pola pemanfaatan alun - alun sebagai ruang terbuka publik di kota Magelang disesuaikan dengan area area yang menjadi titik frekuensi tertinggi. Pemanfaatan ruang terbuka publik diantaranya adalah berolahraga, bermain, berjualan, bersantai, kuliner dan lain sebagainya. Fenomena yang terjadi pada saat ini adalah aktivitas pemanfaatan ruang terbuka publik pada alun alun kota Magelang belum diwadahi oleh setting perabot yang mendukung. Mengingat ruang terbuka publik bersinggungan dengan kehidupan masyarakat sebagai pengguna, maka diperlukan upaya peningkatan sarana dan prasarana untuk mempertahankan keberadaan dan pengendalian dalam pemanfaatannya sehingga dapat menunjang aktivitas para pengguna.

Penelitian ini bertujuan untuk melihat pola pemanfaatan penggunan ruang pada alun-alun kota Magelang berdasarkan tingkat frekuensi para pengguna yang berkegiatan dan melakukan aktivitas. Hal tersebut dilakukan dengan cara melakukan mapping terhadap kegiatan yang dilakukan pada beberapa titik ruang di alun-alun yang menawarkan berbagai fasilitas dan memiliki daya tarik tinggi. Behavioral Mapping merupakan metode yang cocok digunakan dalam penelitian ini, karena dengan metode tersebut dapat diperoleh data mengenai gambaran ruang yang memiliki frekuensi terpadat (Tika, 2018). Penggunaan metode Behavioral Mapping juga dapat melihat bagaimana bentuk adaptasi yang dilakukan oleh pengguna terhadap lingkungan sekitar (Pamungkas, 2020). Berdasarakan latar belakang tersebut, maka dirumuskan bahwa permasalahan yang terjadi adalah bagaimana pola yang tercipta dari adanya frekuensi pergerakan manusia yang melakuakan aktivitas pada ruang-ruang yang memiliki fasilitas di alun-alun kota Magelang. Kemudian setting fisik apa sajakah yang tersedia sehingga terbentuk ruang berkumpul dan sejauh mana faktor-faktor tersebut berperan. Manfaat dari penelitian ini agar dapat memberikan arahan atau guideline sebagai landasan pengembangan desain sarana dan prasaran fisik pada alun-alun kota Magelang agar dapat mewadahi aktivitas dan kegiatan secara optimal 


\section{Metode}

Penelitian ini difokuskan untuk mengkaji pola pemanfaatan ruang terbuka publik di alun-alun kota Magelang. Metode kajian penelitian pola pemanfaatan ruang terbuka publik pada Alun-alun kota Magelang. menggunakan metode kualitatif fenomenologis dengan mengumpulkan data mengenai pola pemanfaatan ruang terbuka alun-alun kota Magelang. Pengumpulan data dilakukan dengan cara survei lapangan (data primer), dan studi pustaka (data sekunder). Data primer didapat dengan cara pengamatan langsung terhadap aktivitas pengguna di alun-alun kota Magelang. Pengamatan pertama yang dilakukan berupa: identifikasi terhadap aktivitas dan kegiatan yang dilakukan oleh para pengguna dan identifikasi terhadap setting fisik atau jenis fasilitas yang ditawarkan pada lingkungan sekitar. Data sekunder didapat dari studi pustaka berupa jurnal, buku, dan informasi lain dari internet. Studi pustaka yang dicari antara lain: kajian ruang terbuka, pola aktivitas dan teknik survey behavioral maaping. Teknis utnuk analisis menggunakan metode behavioral mapping dilakukan dengan langkah sebgai berikut:

1. Menggambarkan dalam bentuk sketsa bagaimana letak setting lingkungan atau fasilitas yang tersebar di alun-alun kota Magelang

2. Melakukan mapping kegiatan dan aktivitas pengguna dengan memberikan gambaran titik titik pergerakan pada ruang yang digunakan

3. Melakukan analisis terhadap gambaran persebaran aktivitas dengan melihat penggunan ruang yang memiliki frekuensi kepadatan tinggi berdasarkan periode waktu tertentu

4. Dari hasil analisa maka dapat ditarik kesimpulan penggunan ruang yang memiliki daya tarik tertinggi akan mengalami frekuensi kepadatan yang cukup tinggi, sehingga dapat diketahui bentuk pola dari pemanfaatan alun-alun kota Magelang sebagai ruang publik

\section{Hasil dan Pembahasan}

Pada tahun 2002, Pemerintah Kota Magelang menyusun masterplan alun-alun kota Magelang, yang kemudian dijadikan sebagai dasar untuk kegiatan renovasi alun-alun. Konsep dasar masterplan tersebut adalah untuk menjadikan alun-alun sebagai pusat kegiatan publik bagi warga kota. Adapun sarana dan prasaran sebagai setting fisik yang nampak pada kondisi eksisting pada Alun alun Kota Magelang dapat dilihat pada (gambar 1) setting fsik tersebut antara lain:

1. Menara air

Menara air yang menjulang setinggi lebih kurang 15 digunakan oleh PDAM kota Magelang sebagai tempat penampungan air yang sanggup memenuhi kebutuhan akan air bagi warga kota Magelang. Menara air minum dengan desain kolonial yang unik djadikan sebagai salah satu ikon landmark kota Magelang.

2. Taman Kuliner

Taman kuliner berjajar di sebleah utara alun -alun dimana para pengguna melakukan aktifitas makan dan minum dengan setting perabot meja, kursi, dan gerobak penjual makanan

3. Giant Font

Giant font terletak pada sisi timur, dimana terdapat ornamen raksasa dengan tulisan Magelang dan banyak digunakan pengunjung untuk tempat yang berfoto-foto.

4. Taman Bunga

Pada area taman bunga didominasi oleh beberapa ornament bunga hias berwarna warni

5. Area Angkringan

Pada pagi hari area ini difungsikan sebagai jogging track, namun pada malam hari area ini beralih fungsi menjadi tempat orang berjualan angkringan khas kota Magelang

6. Dancing fountain

Adanya pertunjukan air mancur menjadi atraksi sebagai daya tarik pengguna Alun-alun 


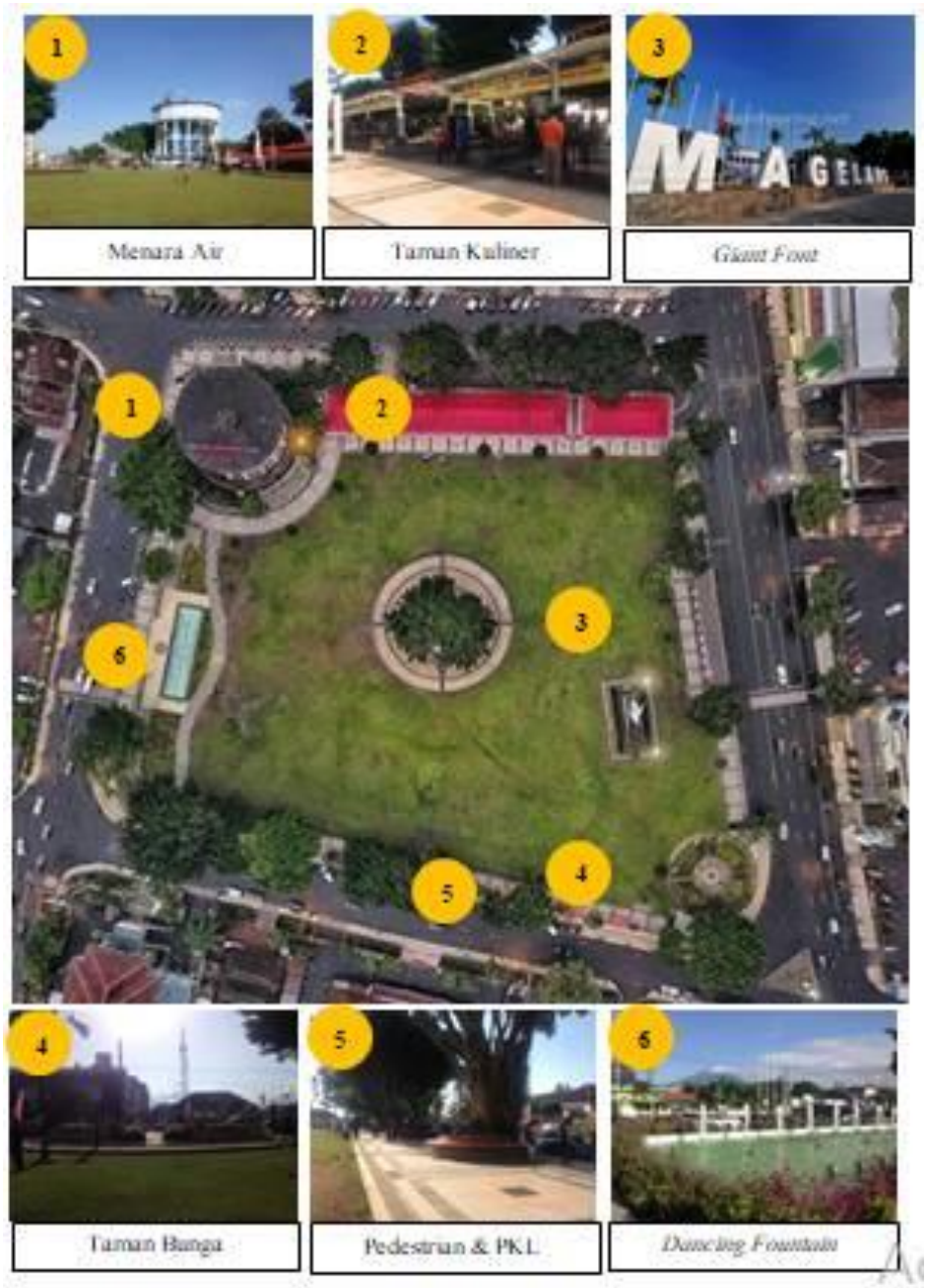

Gambar 1. Setting Fisik Alun - Alun Kota Magelang Sumber: Penulis, 2019

Adapun pembagian segmen setting fisik pada lokasi pengamatan dibagi menjadi 4 segmen, yaitu segmen utara, timur, selatan dan barat dapat dilihat pada (Gambar 2) sebagai berikut :

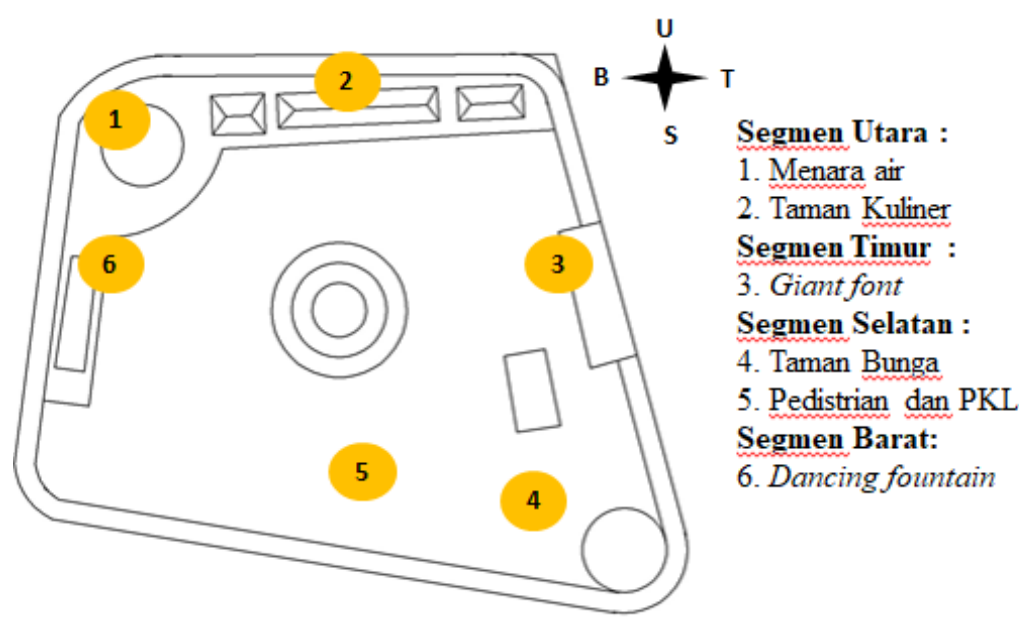

Gambar 2. Pembagian Segmen Setting Fisik

Sumber: Penulis, 2019 


\section{Analisis Pengguna dan Aktivitas}

Ruang terbuka publik sebagai ruang milik masyarakat bersama yang berfungsi sebgaai wadah melakukan aktivitas fungsional dan ritualnya dalam suatu ikatan komunitas (Carr, 1992). Aktivitas pada ruang publik dapat dianalisa dalam empat komponen yaitu (1) Aktivitas sesungguhnya (2) Aktivitas spesifik untuk melakukannya, (3) Aktivitas tambahan, berdampingan atau terasosiasi yang mana menjadi bagian dari sistem aktivitas, (4) Aktivitas simbolik (Rapoport, 1982)

Adapun analisis terhadap pengguna dan aktivitas yang dilakukan pada Alun -alun kota Magelang dapat dijabarkan pada table berikut:

Tabel 1. Analisis Pengguna dan Aktivitas

\begin{tabular}{|c|c|c|}
\hline No & Pengguna & Aktivitas \\
\hline 1 & Anak Kecil & $\begin{array}{l}\text { Bermian sepeda } \\
\text { Bermian kerjar - kejaran } \\
\text { Bermain balon } \\
\text { Melihat pertunjukan dancing fountain }\end{array}$ \\
\hline 2 & Remaja & $\begin{array}{l}\text { Duduk - duduk dan bersantai } \\
\text { Makan di angringan } \\
\text { Makan di PKL } \\
\text { Berfoto } \\
\text { Sepak Bola }\end{array}$ \\
\hline 3 & Orang Tua & $\begin{array}{l}\text { Berolahrga, jogging, senam } \\
\text { Makan di PKL } \\
\text { Berfoto }\end{array}$ \\
\hline 4 & Pasangan & $\begin{array}{l}\text { Duduk - duduk dan bersantai } \\
\text { Makan di angringan } \\
\text { Makan di PKL } \\
\text { Berfoto } \\
\text { Melihat pertunjukan dancing fountain }\end{array}$ \\
\hline 5 & Keluarga & $\begin{array}{l}\text { Duduk - duduk dan bersantai } \\
\text { Makan di angringan } \\
\text { Makan di PKL } \\
\text { Berfoto }\end{array}$ \\
\hline 6 & Pedagang & $\begin{array}{l}\text { Berjualan } \\
\text { Makan Minum } \\
\text { Bersantai } \\
\end{array}$ \\
\hline
\end{tabular}

Sumber: Analisis Penulis, 2019

Setelah melakukan analisis terhadap pengguna dan jenis aktivitas yang dilakukan pengkategorian aktivitas kemudian dilakukan analisis terhapat setting perabot. Setting diartikan sebagai tatanan pada suatu lingkungan yang keberadaanya dapat mempengaruhi manusia dalam berperilaku. Hal tersebut berarti apabila dalam tempat yang sama, perilaku manusia dapat berbeda beda jika tatanan setting nya juga berbeda (Darmawan,2018). Kategori aktivitas dibagi menjadi kategori atraksi, olahraga. kuliner dan permainan anak. 
Tabel 2. Analisis Setting Fisik

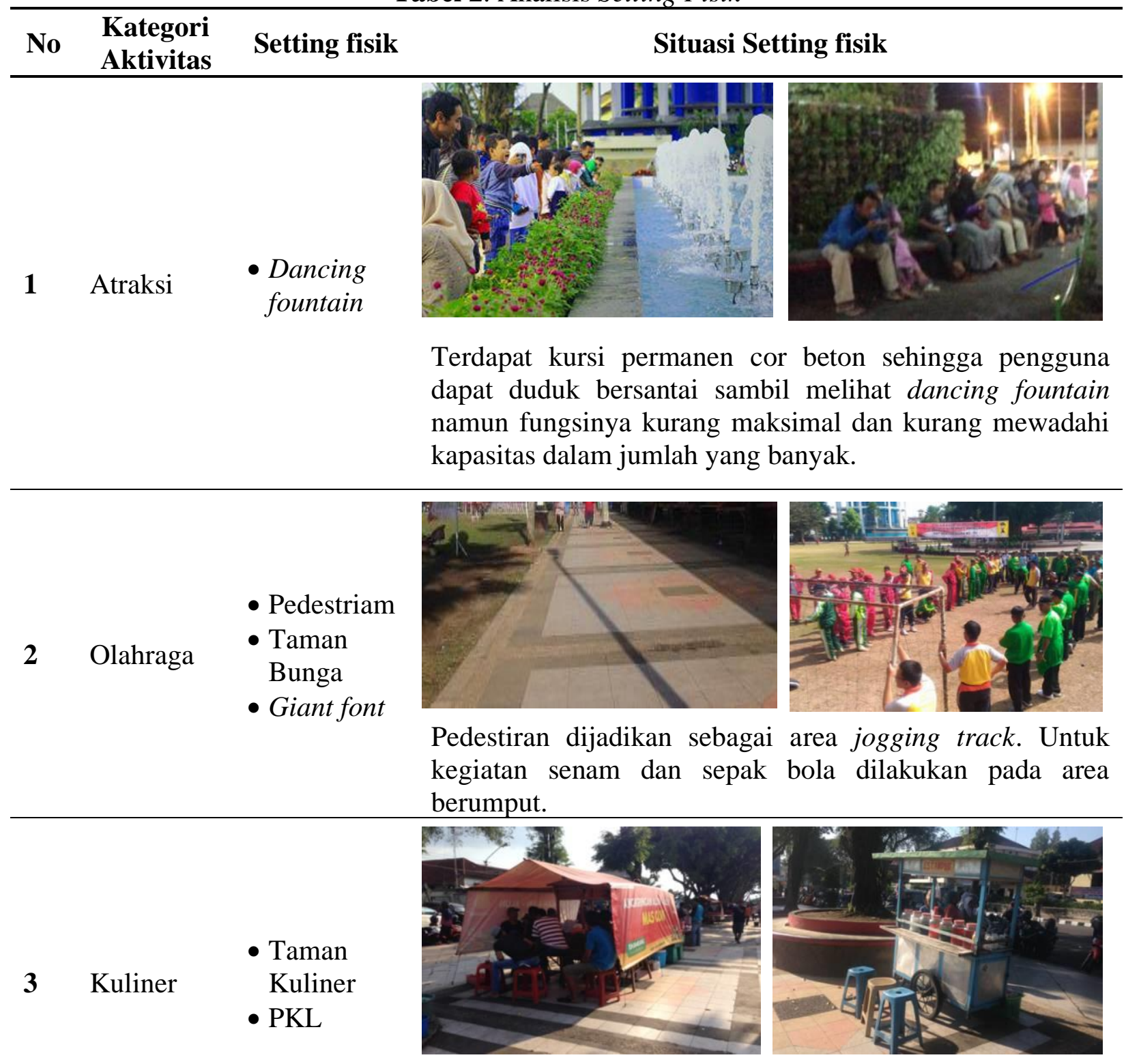

Pada kategori aktivitas kuliner didominasi oleh pedagang pedangan yang berjualan menggunan gerobak dan tenda.

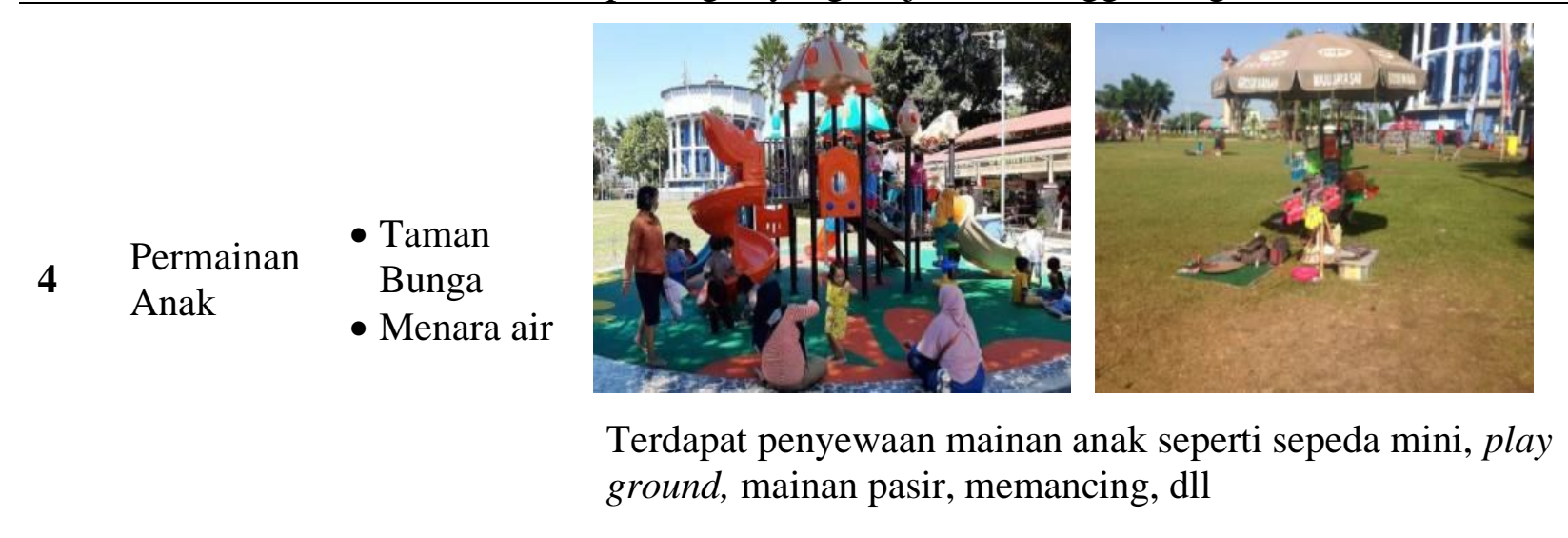

Sumber: Analisis Penulis, 2019 


\section{Analisis Behavioral Mapping}

Behavioral Mapping merupakan sketsa pemetaan perilaku mengenai suatu area dimana terdapat manusia melakukan aktivitasnya (Porteous, 1997). Pemetaan perilaku dilakukan dengan melakukan penggambran dalam bentuk sketsa atau diagram pada area manusia berkegiatan (Rofiq, 2018). Tujuan dari Behavioral Mapping adalah mengidentifikasikan jenis dan frekuensi perilaku, serta menunjukkan kaitan antara perilaku tersebut dengan wujud perancangan yang spesifik (Fitria, 2018). Jenis perilaku yang dipetakan yaitu pola perjalanan melalui prosedur: (1) Membuat sketsa area atau setting yang akan diobservasi, (2) Membuat definisi mengenai perilaku yang diamati, dihitung, maupun didiskripsikan, (3) Membuat rencana mengenai waktu pengamatan pada periode tertentu (Agustapraja, 2018). Periode waktu ditentukan berdasarkan jumlah terbanyak dari hasil pemetaan perilaku pada suatu lokasi (Wahyuni, 2004).

Pemataan aktivitas dilakukan pada dua masa, yaitu weekdays dan weekend dimana terjadi beberapa perbedaan intensitas jumlah pengguna dan aktivitas. Selanjutnya pembagian massa ditentukan oleh perode waktu penelitianyaitu pagi hari, siang hari, dan malam hari dengan durasi perhitungan sample selama 3 jam pengamatan. Indikator yang dipakai untuk menganalisis menggunakan teknik behavioral mapping dapat dilihat pada (table 3) berikut ini:

Tabel 3. Indikator dan variabel

\begin{tabular}{|c|c|c|}
\hline No & Indikator & Variabel \\
\hline 1 & Behavioral Mapping & $\begin{array}{ll}\text { - } & \text { Segemn Utara } \\
\text { - } & \text { Segmen Timur } \\
\text { - } & \text { Segmen Selatan } \\
\text { - } & \text { Segmen Barat } \\
\end{array}$ \\
\hline 2 & Pengguna & $\begin{array}{l}\text { - } \text { Anak kecil } \\
\text { - } \text { Remaja } \\
\text { - Orang Tua } \\
\text { - } \quad \text { Pasangan } \\
\text { - Keluarga } \\
\text { - } \text { Pedagang } \\
\end{array}$ \\
\hline 3 & $\begin{array}{l}\text { Kategori Aktivitas yang } \\
\text { dilakukan }\end{array}$ & $\begin{array}{ll}\text { - } & \text { Atraksi } \\
\text { - } & \text { Olahraga } \\
\text { - } & \text { Kuliner } \\
\text { - } & \text { Permainan Anak }\end{array}$ \\
\hline
\end{tabular}

Sumber: Analisis Penulis, 2019 
Tabel 4. Analisis Behavioral Mapping Weekdays

\begin{tabular}{cccc} 
& Pukul 06.00 WIB & Pukul 14.00 WIB - & Pukul 19.00 WIB - \\
Indikator & 09.00 WIB & 17.00 WIB & 22.00 WIB \\
& (Pagi) & (Sore ) & (Malam) \\
\hline
\end{tabular}

\section{WEEKDAYS}

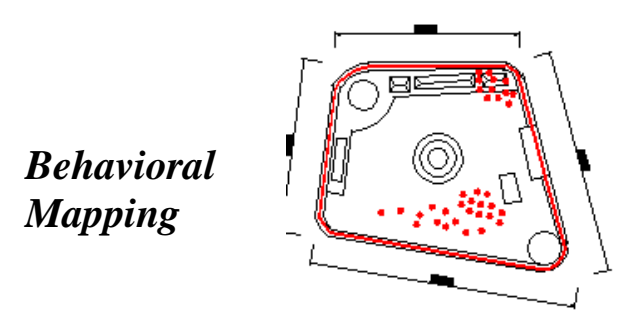

Aktivias dominan terjadi pada sisi sebelah utara dan selatan. Sisi utara adalah taman kuliner dimana orang membeli sarapan. Sisi selatan adalah area rumput yang digunakan untuk berolahraga senam dan sepak bola

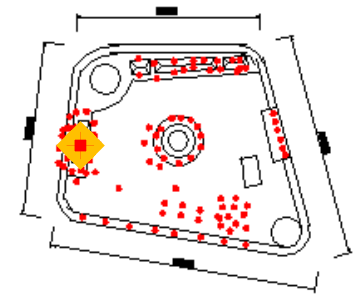

Aktivias dominan terletak pada sisi sebelah timur yaitu area dancing fountain dimana dilakukan pertunjukan pada pukul 16.00 WIB

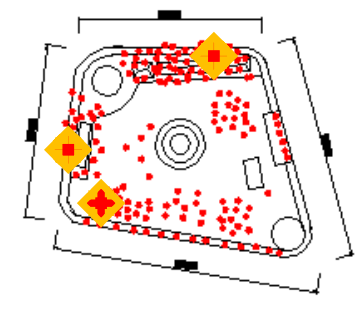

Aktivias dominan terletak pada sisi utara, timur dan selatan. Sisi utara adalah Taman Kuliner, timur adalah pertunujkan dancing fountain, dan selatan adalah area pedestrian dan PKL

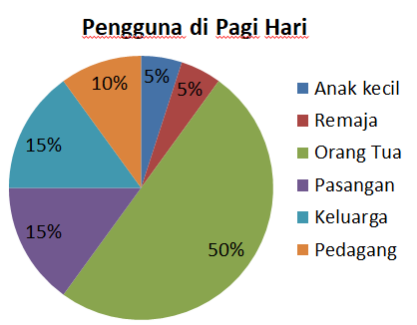

Pengguna yang mendominasi pada pagi hari adalah orang tua

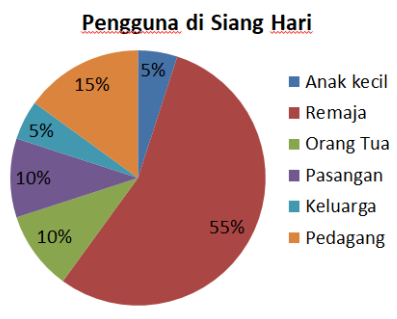

Pengguna yang mendominasi pada siang hari adalah remaja

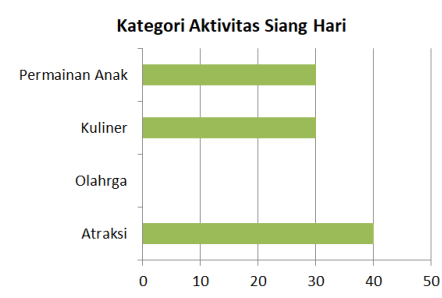

Aktivitas yang dominan pada siang hari adalah atraksi

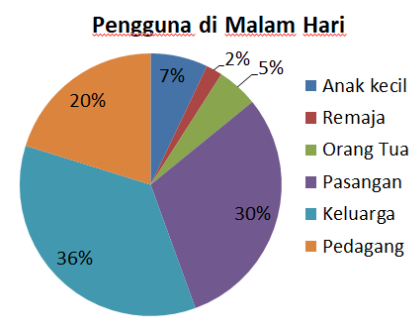

Pengguna yang mendominasi pada malam hari adalah keluarga

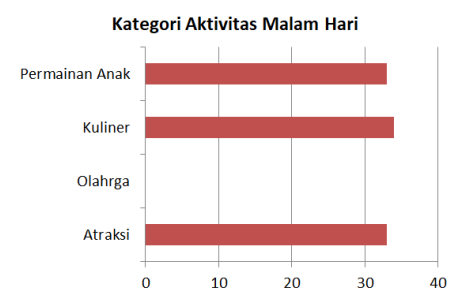

Aktivitas yang dominan pada malam hari adalah kuliner 
Tabel 5. Analisis Behavioral Mapping Weekend

\begin{tabular}{cccc} 
& Pukul 06.00 WIB & Pukul 14.00 WIB - & Pukul 19.00 WIB -22.00 \\
Indikator & 09.00 WIB & 17.00 WIB & WIB \\
& (Pagi) & (Sore $)$ & (Malam) \\
\hline
\end{tabular}

\section{WEEKEND}

\section{Behavioral Mapping}

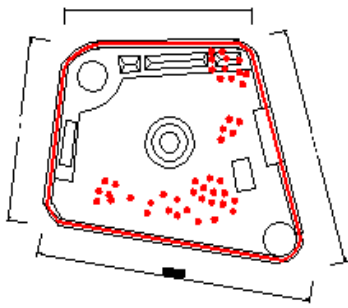

Aktivitas dominan terjadi pada sisi sebelah utara dan selatan. Sisi utara adalah taman kuliner dimana orang membeli sarapan. Sisi selatan adalah area rumput yang digunakan untuk berolahraga senam dan sepak bola

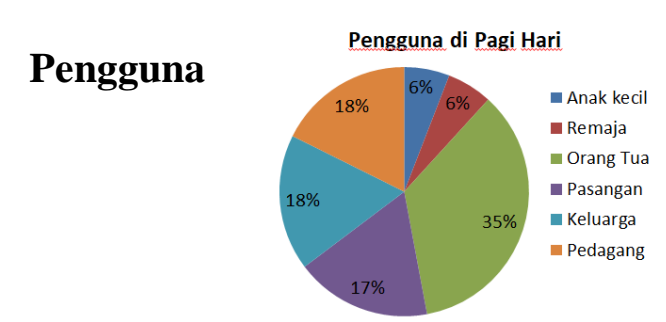

Pengguna yang mendominasi pada pagi hari adalah orang tua dan keluarga

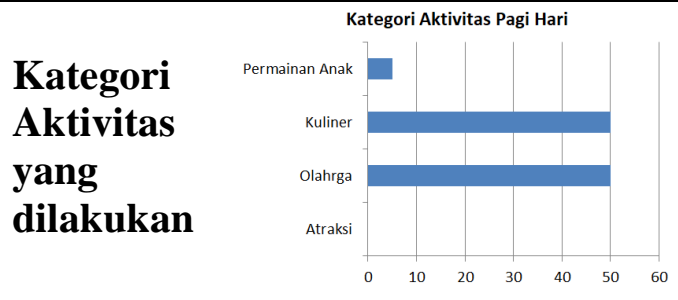

Aktivitas yang dominan pada pagi hari adalah olahraga dan kuliner

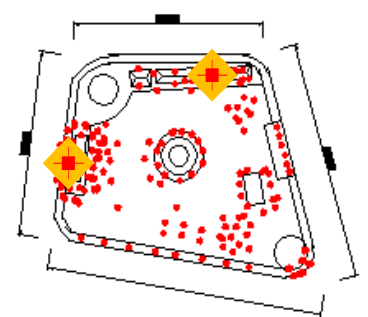

Aktivitas dominan terletak pada sisi sebelah timur yaitu area dancing fountain dan sebelah utara yaitu taman kuliner.

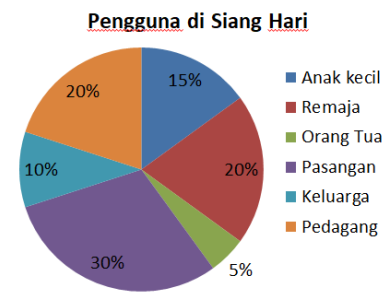

Pengguna yang mendominasi pada siang hari adalah pasangan

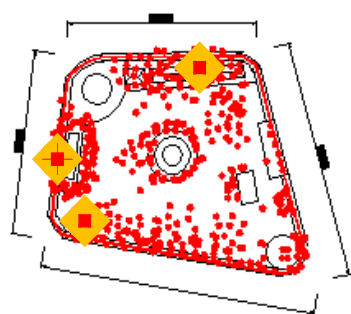

Aktivias dominan terletak pada sisi utara, timur dan selatan. Sisi utara adalah Taman Kuliner, timur adalah pertunujkan dancing fountain, dan selatan adalah PKL

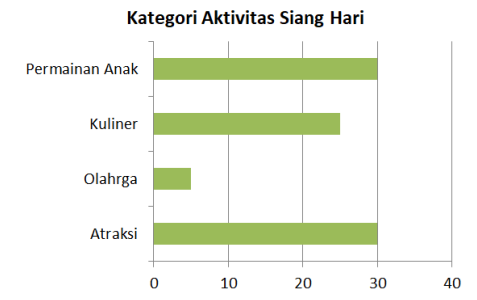

Aktivitas yang dominan pada siang hari adalah atraksi dan permainan anak

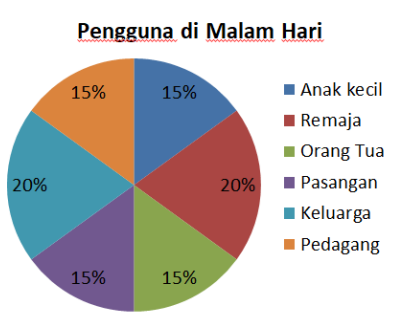

Pengguna yang mendominasi pada malam hari adalah keluarga dan remaja

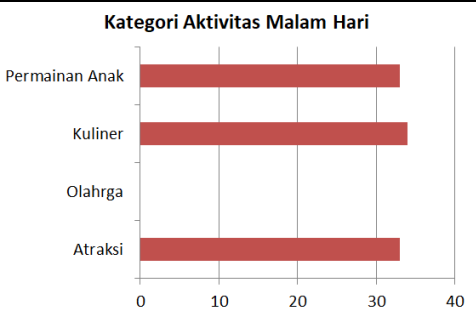

Aktivitas yang dominan pada malam hari adalah kuliner

Sumber: Analisis Penulis, 2019 
Dilihat dari Tabel 4, dapat diketahui bahwa intensitas tertinggi pola pemanfaatan ruang di Alun -alun kota Magelang didominasi pada malam hari di waktu weekend dan dimoniasi oleh 3 titik area yaitu: utara, timur dan selatan.

\section{Sisi Barat (Dancing Fountain)}

Karena setting fisik yang ditawarkan tidak mewadahi banyaknya pengguna yang melakukan kegiatan sehingga timbul pola perilaku pengguna yang cenderung dapat merusak tatanan fisik taman Alun - Alun Magelang. Sehingga pengguna cenderung duduk sembarangan, berdiri, memanjat sarana dan prasarana seperti pot, dan kursi hanya untuk melihat air mancur.
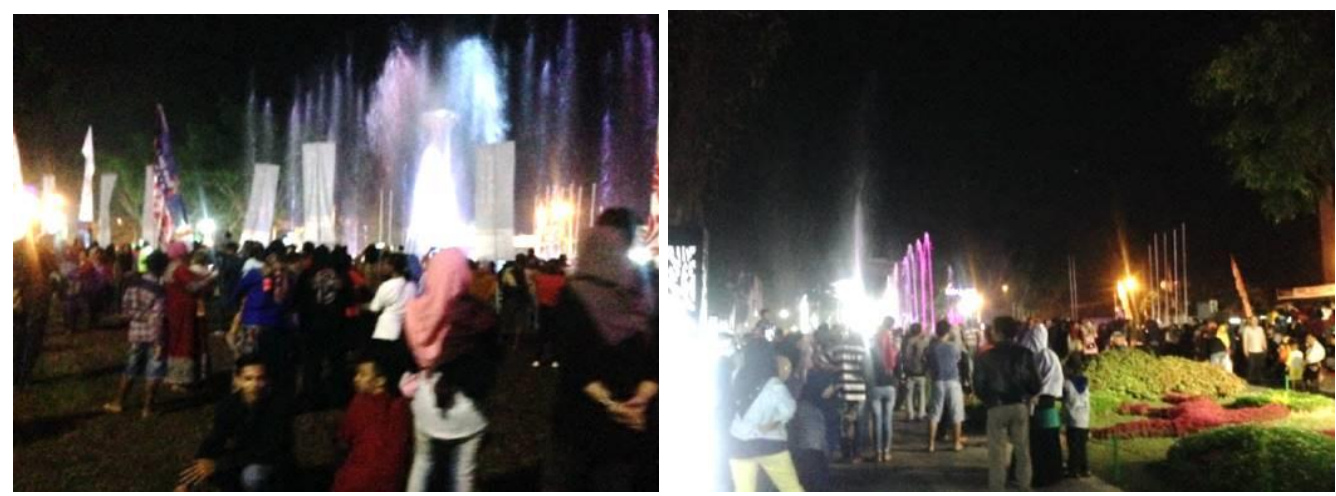

Gambar 3. Aktivitas Pengguna pada Sisi Timur

Sumber: Penulis, 2019

\section{Sisi Utara (Taman Kuliner)}

Pada area kuliner mengalami tingkat kepadatan yang tinggi karena karakteristik pengguna yang datang adalah keluraga untuk sekedar makan bersama dan menikmati suasana malam hari di alun - alun Kota Magelang.
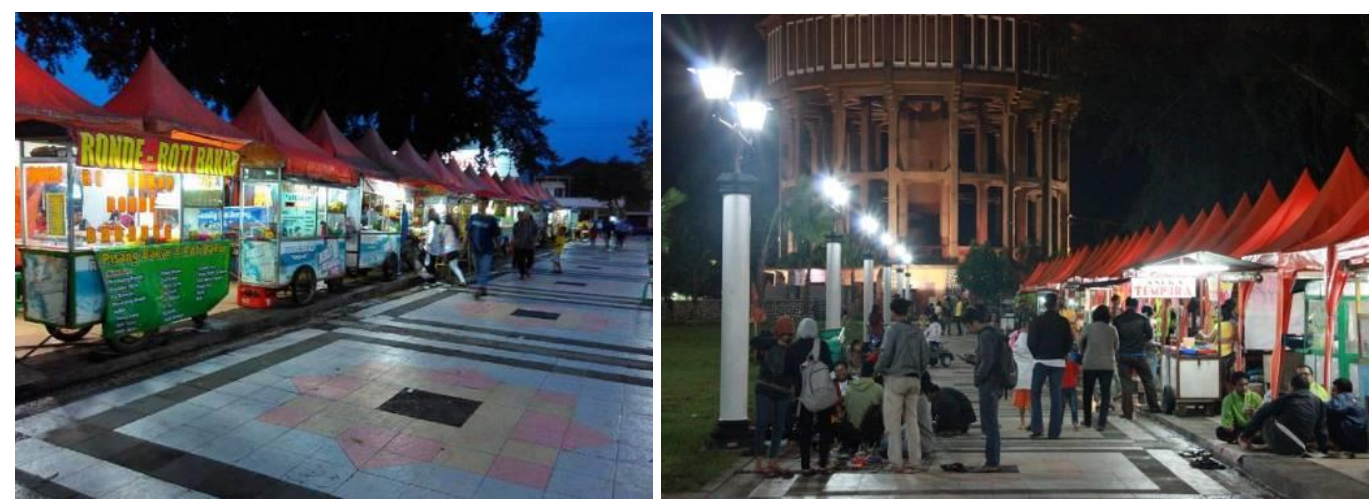

Gambar 4. Aktivitas Pengguna pada Sisi Utara

Sumber: Penulis, 2019

\section{Sisi Selatan (Area PKL)}

Setting fisik pada area angkringan cenderung berdampak pada kurang nya perabot seperti meja kursi yang mendukung sehinga banyak pengguna yang memanfatkan duduk lesehan dan menyebabkan pencemaran lingkungan karena membuang sampah sembarangan. 

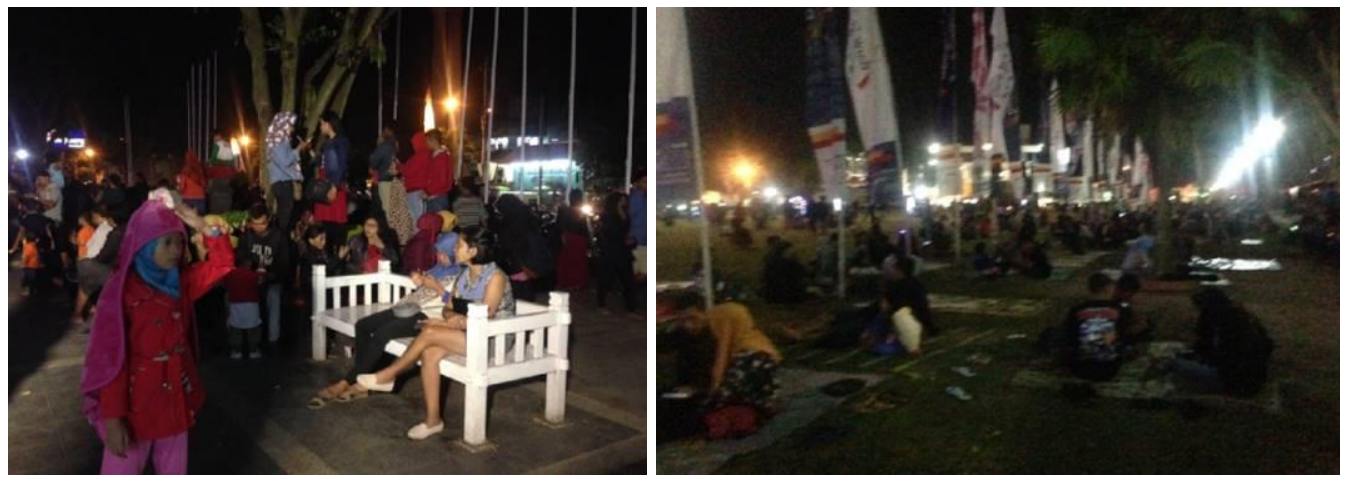

Gambar 5. Aktivitas Pengguna pada Sisi Selatan

Sumber: Penulis, 2019

\section{Kesimpulan}

Berdasarkan hasil analisis menggunakan teknik behavioral mapping, maka dapat disimpulkan bahwa pola pemanfaatan Alun -alun seabagai ruang terbuka publik di kota Magelang didominasi oleh kegiatan atraksi dan kuliner yang memiliki intensitas penggunan tinggi pada masa weekend dan malam hari. Dimana pengguna menghabiskan waktu akhir pekan untuk berwisata di Alun -alun Kota Magelang. Adanya dancing fountain sebagai atraksi utama menyebabkan orang untuk berkerumun menyakaksikan pertunjukan dengan waktu yang sudah terjadwalkan, pada area tersebut terdapat banyak pot bunga serta kursi permanen sehingga menyebakan pengunjung melakukan banyak aktivitas disana. Demikian juga pada area kuliner, dikarenakan adanya setting perabot berupa meja dan kursi menyebabkan pengunjung tertarik untuk duduk dan menghabiskan waktu yang lama pada tempat tersebut.

\section{Daftar Acuan}

Agustapraja, H. R. (2018, Maret). Studi Pemetaan Pelaku (Behavioral Mapping) Pejalan Kaki Pada Pedestrian Alun Alun Kota Lamongan. Jurnal Civilla, Vol 3 No 1, 134-139.

Anggita , N. M., \& Ardiana , Y. P. (2017, Oktober). Analisis Pemanfaatan Ruang Publik pada Akitivitas Penduduk Permukiman Mlaten Kota Semarang. Jurnal Planologi, Vol 14, No 2, 102116.

Carr, S. M. (1992). Public Space. In Public Spac. Australia: Press Syndicate of University of Cambridge.

Darmawan. (2018). Pola Pemanfaatan Ruang Terbuka pada Pemukiman Kampung Kota. Vitruvian Jurnal Arsitektur, Vol. 07 No. 3, 127-136

Fitria, T. A. (2018, September). Pengaruh Setting Ruang Terhadap Perilaku Pengguna dengan Pendekatan Behavioral Mapping. Jurnal Arsitektur Perencanaan UNISA, Vol 2 No 2 , 183-206.

Pamungkas, H. (2020). Behavioral Mapping dan Adaptasi terhadap Lingkungan PADA Squartter Settlements. Jurnal Arsiketkur NALARs, Vol 19 N0 2, 115-130

Porteous. (1997). Environment and Behavior. In Planning And Everyday Urban Life. Massachusetts: Addison Wasley .
Rapoport, A. (1982). Towards a Man Environment Approach to Urban Form and Design. In Human Aspect of Urban Form. USA: Pergamon Press.

Rofiq, Hammam A (2018). Studi Pemetaan Perilaku (Behavioral Mapping) pada Pedestrian Alunalun Kota Lamongan. Jurnal CIIVILLA Vol. 3 No $1,135-139$

Tika, A. F. (2018). Pengaruh Seting Ruang Terhadap Perilaku Pengguna Dengan Pendekatan Behavioral Mapping. Jurnal Arsitektur dan Perencanaan (Juara), Vol 1 No 2, 183-206.

Wahyuni, D. S. (2004). Studi Behaviour Setting dan Behavioral Mapping pada Taman kota. Bogor: Departemen Budi Daya Pertanian IPB. 